\title{
Esporotricose cutânea experimental: Avaliação in vivo do itraconazol e terbinafina
}

\author{
Experimental cutaneous sporotrichosis: in vivo evaluation \\ of itraconazole and terbinafine
}

\author{
Tatiana de Ávila Antunes ${ }^{1}$, Márcia de Oliveira Nobre², Renata Osório de Faria ${ }^{3}$, \\ Ana Raquel Mano Meinerz ${ }^{4}$, Anelise Afonso Martins ${ }^{3}$, Marlete Brum Cleff', \\ Cristina Gevehr Fernandes ${ }^{6}$ e Mário Carlos Araújo Meireles ${ }^{5}$
}

\begin{abstract}
RESUMO
0 estudo objetivou avaliar a atividade in vivo do itraconazol e terbinafina no tratamento da esporotricose cutânea experimental. Foram utilizados 80 ratos Wistar divididos em quatro grupos (TERB20, TERB30, ITRA e CONT) inoculados no coxim plantar esquerdo com 0,2ml de solução contendo 2x103 células de Sporothrix schenckii/ml e tratados com terbinafina (20 e 30mg/kg), itraconazol (10mg/kg) e placebo durante 13 semanas. As lesões do sítio de inoculação foram avaliadas e mensuradas semanalmente, assim como a disseminação das mesmas. Após foi realizada análise micológica e histopatológica. Os resultados demonstraram que os animais do grupo ITRA diferiram estatisticamente em todos os parâmetros avaliados em relação ao CONT. Em relação à terbinafina, não houve diferenças estatísticas entre os grupos tratados e controle. Pode-se confirmar a boa atividade do itraconazol no tratamento da esporotricose e a pouca eficácia da terbinafina nas doses utilizadas, sendo necessários mais estudos com este antifúngico.
\end{abstract}

Palavras-chaves: Esporotricose. Sporothrix schenckii. Terbinafina. Itraconazol.

\begin{abstract}
The aim of this study was to evaluate the in vivo activity of itraconazole and terbinafine for treating experimental cutaneous sporotrichosis. Eighty Wistar rats were used, divided into four groups (TERB20, TERB30, ITRA and CONT). They were inoculated in the left plantar pad with $0.2 \mathrm{ml}$ of solution containing $2 \times 10^{3}$ cell/ml of Sporothrix schenckii and treated with terbinafine (20 and $30 \mathrm{mg} / \mathrm{kg}$ ), itraconazole (10 mg/kg) or placebo for 13 weeks. The lesions at the inoculation site were evaluated and measured weekly, along with their dissemination. Mycological and histopathological analyses were performed subsequently. The results showed that the animals in the ITRA group differed statistically in all parameters evaluated, in relation to CONT. For terbinafine, there were no statistical differences between the treated and control groups. It could be confirmed that itraconazole presented good activity for treating sporotrichosis, while terbinafine was ineffective for this disease at the doses used. However, more studies on the latter antifungal agent are needed.
\end{abstract}

Key-words: Sporotrichosis. Sporothrix schenckii. Terbinafine. Itraconazole.

A esporotricose, micose subcutânea de evolução subaguda ou crônica, tem como agente etiológico o fungo dimórfico Sporothrix schenckii acometendo o homem e uma grande variedade de animais, principalmente 0 felino doméstico. 0 agente apresenta distribuição mundial sendo encontrado no solo rico em matéria orgânica, vegetais e cascas de árvores?

1. Pós-Graduação em Veterinária, Faculdade de Veterinária, Universidade Federal de Pelotas, Pelotas, RS. 2. Departamento de Clínicas Veterinária, Faculdade de Veterinária, Universidade Federal de Pelotas, Pelotas, RS. 3. Pós-Graduação em Ciências Veterinárias, Universidade Federal do Rio Grande do Sul, Porto Alegre, RS. 4. Laboratório de Doenças Infecciosas (Setor de Micologia) Faculdade de Veterinária, Universidade Federal de Pelotas, Pelotas, RS. 5. Departamento de Veterinária Preventiva, Faculdade de Veterinária, Universidade Federal de Pelotas, Pelotas, RS. 6. Departamento de Patologia Animal, Faculdade de Veterinária, Universidade Federal de Pelotas, Pelotas, RS.

Endereço para correspondência: Dra. Tatiana de Ávila Antunes. Rua Três de Maio 473, 96010-620 Pelotas, RS

Tel: $55533227-8477$

e-mail: tatdavila@bol.com.br

Recebido em: 09/01/2009

Aceito em 30/10/2009
Até 1990, a forma mais frequente de transmissão da esporotricose era através da inoculação traumática ou acidental de matérias vegetais contaminadas com o agente, sendo, portanto, considerada uma micose ocupacional. No entanto, atualmente, são cada vez mais frequentes os relatos zoonóticos envolvendo os felinos domésticos, especialmente machos não castrados e de vida livre, devido aos hábitos inerentes da espécie. Os relatos demonstram que a transmissão ocorre, principalmente, através de arranhadura, mordedura ou contato direto com lesões dos felinos enfermos. Sugere-se que a transmissão é facilitada devido ao grande número de leveduras presentes nas lesões dos animais acometidos, sendo que o agente já foi isolado da cavidade bucal e unhas, destacando o risco de transmissão por essas vias ${ }^{1415}$.

o itraconazol, antifúngico do grupo dos triazóis, tem demonstrado eficácia no tratamento da esporotricose humana nas diferentes formas da doença e em animais, principalmente felinos. Porém, o uso indiscriminado deste antifúngico resultou no surgimento de isolados resistentes, sendo crescentes os relatos de falhas terapêuticas no uso do itraconazol tanto em animais 
como em humanos. A terbinafina, uma alilamina, vem sendo avaliada quanto a sua atividade frente ao Sporothrix schenckii, demonstrando intensa ação in vitro frente ao agente e atualmente vem sendo estudada para o tratamento da esporotricose em humanos ${ }^{589}$. No entanto, na clínica Veterinária ainda são escassos os estudos que confirmem a ação da terbinafina no tratamento de micoses em felinos e caninos ${ }^{13}$.

Considerando a esporotricose uma importante zoonose fúngica, assim como os problemas relacionados à terapêutica da micose, o estudo teve como objetivo avaliar e comparar a atividade in vivo do itraconazol e da terbinafina no tratamento da esporotricose cutânea experimental.

\section{MATERIAL E MÉTODOS}

Foram utilizados 80 ratos Wistar/UFPel, machos, 70 dias, peso médio de 350 gramas, alojados no Biotério Central da UFPel com dieta e água ad libitum. Foram divididos em quatro grupos de 20 animais, sendo eles: tratado terbinafina, nas doses de 20 e $30 \mathrm{mg} /$ kg diluído em água destilada estéril (TERB20 e TERB30); tratado itraconazol na dose de $10 \mathrm{mg} / \mathrm{kg}$ diluído em água destilada estéril (ITRA) e grupo controle tratado com água destilada estéril (CONT) conforme metodologia descrita por Meiner $z^{8}$. 0 inóculo fúngico foi preparado a partir de um isolado de Sporothrix schenckii proveniente de esporotricose cutânea de felino doméstico (Felis cattus). Para a obtenção do inoculo fúngico, esse isolado foi cultivado em meio líquido BHI durante 10 dias a $37^{\circ} \mathrm{C}$ e mantido sob agitação para obtenção da forma leveduriforme do fungo e posteriormente o inóculo foi padronizado em 2x103 células de Sporothrix schenckii/ml. A suspensão fúngica foi inoculada pela via subcutânea no coxim plantar esquerdo com $0,2 \mathrm{ml}$ de suspensão do inoculo. 0 tratamento iniciou duas semanas após a inoculação, quando todos já apresentavam lesões características de esporotricose cutânea, com a presença de lesões nodulares e exsudato purulento castanho-avermelhado. A administração dos fármacos e placebo nas doses previamente descritas foi realizada pela via oral, com auxílio de sonda orogástrica uma vez ao dia, durante 13 semanas.

Os animais foram observados diariamente, sendo mensurado semanalmente o sítio de inoculação com auxílio do paquímetro, para verificar o diâmetro externo da lesão e avaliou-se a presença de lesões cutâneas disseminadas características de esporotricose. Foram feitas três necropsias no decorrer do estudo, correspondendo às semanas 9,12 e 15 respectivamente em oito, quatro e oito animais de cada grupo para a análise micológica e histopatológica. Foram colhidas amostras do ponto de inoculação, testículos, linfonodos, fígado, baço e outros órgãos quando tivessem comprometidos. A análise micológica consistiu no cultivo das amostras em placas de Petri contendo ágar Sabouraud dextrose acrescido de cloranfenicol e cicloheximida e mantidos a $25^{\circ} \mathrm{C}$ e $37^{\circ} \mathrm{C}$ durante 10 dias para caracterização macro e micromorfológica do Sporothrix schenckii e confirmação do dimorfismo. Para o exame histopatológico, as amostras foram acondicionadas em formol a 10\%, sendo posteriormente incluídas em parafina e realizadas colorações de eosina-hematoxilina (HE) e ácido periódico-Schiff (PAS) para visualização em microscópio ótico.

A avaliação estatística foi realizada utilizando o programa Statistix 7.0 (Statistix, 2000), através da distribuição das frequências semanais das médias para os diâmetros das lesões relacionadas com os tratamentos. Para estimar as diferenças entre os tratamentos por semana, usou-se a análise da variância pelo método Kruskal-Wallis, para dados não paramétricos e comparação de médias pelo Teste de Tukey.

\section{RESULTADOS}

0 grupo ITRA apresentou o maior diâmetro $(12,3 \mathrm{~mm})$ nas semanas 2 e 3 chegando ao final do experimento com $8 \mathrm{~mm}$ diferindo estatisticamente $(\mathrm{P}<0,05)$ do grupo CONT e do TERB20 até o final do experimento e do TERB30 nas semanas 5 a 9 e 11 , 13 e 15. Entretanto, o diâmetro observado para o grupo TERB20 no decorrer das semanas variou de $10,9 \mathrm{~mm}$ a $10,6 \mathrm{~mm}$, enquanto o grupo TERB30 a variação foi de 11,1mm a 11,6mm na última semana. Os resultados das análises estatísticas demonstraram diferenças em relação ao grupo submetido ao tratamento com antifúngico terbinafina em relação ao controle e itraconazol (Tabela 1).

\section{TABELA 1}

Diâmetro do coxim plantar esquerdo de ratos albinos (Rattus novergicus) linhagem Wistar dos grupos ITRA, TERB20, TERB30 e CONT durante o tratamento da esporotricose cutânea experimental.

\begin{tabular}{|c|c|c|c|c|c|c|c|c|}
\hline \multirow[b]{2}{*}{ Semanas } & \multicolumn{2}{|c|}{ ITRA } & \multicolumn{2}{|c|}{ TERB20 } & \multicolumn{2}{|c|}{ TERB30 } & \multicolumn{2}{|c|}{ CONT } \\
\hline & $\begin{array}{l}\text { média } \\
(\mathrm{mm})\end{array}$ & $\begin{array}{c}\mathrm{DP} \\
(\mathrm{mm})\end{array}$ & $\begin{array}{l}\text { média } \\
(\mathrm{mm})\end{array}$ & $\begin{array}{c}\begin{array}{c}\mathrm{DP} \\
(\mathrm{mm})\end{array}\end{array}$ & $\begin{array}{l}\text { média } \\
(\mathrm{mm})\end{array}$ & $\begin{array}{c}\mathrm{DP} \\
(\mathrm{mm})\end{array}$ & $\begin{array}{l}\text { média } \\
(\mathrm{mm})\end{array}$ & $\begin{array}{r}\mathrm{DP} \\
(\mathrm{mm})\end{array}$ \\
\hline 1 & $10,5^{\mathrm{ab}}$ & 1,0 & $10,9^{\mathrm{ab}}$ & 0,8 & $11,1^{\mathrm{a}}$ & 0,9 & $10,3^{b}$ & 0,7 \\
\hline $2^{*}$ & $12,3^{\mathrm{a}}$ & 1,3 & $12,5^{\mathrm{a}}$ & 1,6 & $12,2^{\mathrm{a}}$ & 1,3 & $11,9^{\mathfrak{a}}$ & 1,1 \\
\hline 3 & $12,3^{\mathrm{a}}$ & 1,3 & $12,5^{\mathrm{a}}$ & 1,6 & $12,2^{\mathrm{a}}$ & 1,3 & $12,5^{\mathrm{a}}$ & 1,6 \\
\hline 4 & $10,7^{\mathrm{b}}$ & 1,2 & $12,1^{\mathrm{a}}$ & 1,1 & $10,9^{b}$ & 1,3 & $12,1^{\mathrm{a}}$ & 1,6 \\
\hline 5 & $9,7^{b}$ & 1,3 & $12,1^{\mathrm{a}}$ & 1,7 & $11,4^{\mathrm{a}}$ & 1,4 & $12,4^{\mathrm{a}}$ & 1,5 \\
\hline 6 & $9,2^{\mathrm{b}}$ & 1,3 & $11,8^{\mathrm{a}}$ & 2,0 & $11,7^{\mathrm{a}}$ & 1,6 & $13,0^{\mathrm{a}}$ & 1,4 \\
\hline 7 & $9,4^{b}$ & 1,5 & $12,3^{\mathrm{a}}$ & 1,8 & $11,4^{\mathrm{a}}$ & 1,3 & $12,3^{\mathrm{a}}$ & 1,7 \\
\hline 8 & $8,9^{\mathrm{c}}$ & 1,4 & $11,2^{\mathrm{ab}}$ & 2,0 & $10,9^{\mathrm{b}}$ & 1,1 & $12,4^{\mathrm{a}}$ & 1,7 \\
\hline 9 & $8,7^{\mathrm{c}}$ & 1,7 & $11,5^{\mathrm{ab}}$ & 2,1 & $10,7^{\mathrm{b}}$ & 1,4 & $12,4^{\mathrm{a}}$ & 1,6 \\
\hline 10 & $8,7^{\mathrm{b}}$ & 1,8 & $11,5^{\mathrm{a}}$ & 2,5 & $11,0^{\mathrm{ab}}$ & 1,9 & $12,0^{\mathrm{a}}$ & 2,6 \\
\hline 11 & $8,9^{\mathrm{b}}$ & 1,9 & $11,5^{\mathrm{a}}$ & 2,1 & $11,2^{\mathrm{a}}$ & 1,2 & $12,4^{\mathrm{a}}$ & 2,4 \\
\hline 12 & $9,0^{\mathrm{b}}$ & 2,0 & $11,7^{\mathrm{a}}$ & 2,1 & $10,8^{\mathrm{ab}}$ & 1,8 & $12,0^{\mathrm{a}}$ & 2,0 \\
\hline 13 & $7,7^{\mathrm{b}}$ & 0,8 & $11,5^{\mathrm{a}}$ & 2,2 & $10,2^{\mathrm{a}}$ & 1,3 & $12,3^{\mathrm{a}}$ & 2,1 \\
\hline 14 & $8,1^{\mathrm{b}}$ & 0,9 & $10,7^{\mathrm{a}}$ & 1,6 & $10,1^{\mathrm{ab}}$ & 1,2 & $12,2^{\mathrm{a}}$ & 2,1 \\
\hline 15 & $8,0^{\mathrm{c}}$ & 0,5 & $10,6^{\mathrm{b}}$ & 1,8 & $11,6^{a b}$ & 1,5 & $13,0^{\mathrm{a}}$ & 2,2 \\
\hline
\end{tabular}

*início do tratamento com medicamentos.

DP: desvio padrão; ITRA: grupo tratado itraconazol, TERB20: grupo tratado com terbinafina dose $20 \mathrm{mg} / \mathrm{kg}$, TERB30: grupo tratado terbinafina dose $30 \mathrm{mg} / \mathrm{kg}$, CONT: grupo controle, mm: milímetro.

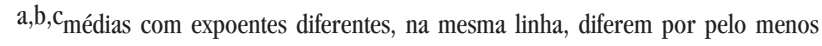
$\mathrm{P}<0,05$. 
Em relação ao acompanhamento de lesões disseminadas de esporotricose, em locais como cauda, face, membros torácicos e pélvicos, assim como aumento dos linfonodos regionais, foi observado que 0 grupo ITRA diferiu estatisticamente $(\mathrm{P}<0,05)$ do grupo CONT nas semanas 7, 8, 9, 10 e 13 do experimento, entretanto, os ratos pertencentes aos grupos TERB20 e TER30 não apresentaram diferenças estatisticamente significativas entre si e em relação ao grupo CONT $(\mathrm{P}<0,05)$ durante o período experimental. 0 grupo TERB20 apresentou uma maior frequência de múltiplas lesões, diferindo $(\mathrm{P}<0,05)$ do grupo ITRA nas semanas $10,13 \mathrm{e}$ 14 e o TERB30 diferiu estatisticamente do grupo ITRA a partir da semana 8 até o final do experimento (Tabela 2).

o Sporothrix schenckii foi retroisolado do ponto de inoculaçã̃o e outras áreas corpóreas nos animais dos grupos TERB20, TERB30 e CONT nas três necropsias realizadas (semanas 9, 12 e 15), enquanto nos animais do grupo ITRA, o retroisolamento do fungo no coxim plantar, tecido cutâneo (cauda, membros pélvicos e torácicos), testículos, linfonodos e vísceras (fígado, baço e pulmão) foi obtido somente na primeira necropsia.

Os achados histopatológicos dos coxins plantares dos grupos TERB20, TERB30, ITRA e CONT estão dispostos na Tabela 3. Os resultados das análises histopatológicas de amostras colhidas de outras regiões cutâneas e órgãos infectados pela disseminação das esporotricose, foram similares as observadas no coxim plantar.
TABELA 2

Frequências de múltiplas lesões em ratos com esporotricose cutânea experimental tratados com itraconazol (ITRA), terbinafina (TERB20 e TERB30) e animais pertencentes ao grupo controle (CONT)

\begin{tabular}{lcccc}
\hline & \multicolumn{4}{c}{ Grupos (\%) } \\
\cline { 2 - 5 } Semanas & ITRA & TERB 20 & TERB 30 & CONT \\
\hline 1,0 & - & - & - & - \\
$2,0^{* *}$ & - & - & - & - \\
3,0 & - & - & - & - \\
4,0 & - & - & - & 10,0 \\
5,0 & - & 20,0 & 25,0 & 30,0 \\
6,0 & - & 20,0 & 25,0 & 45,0 \\
$7,0^{* * *}$ & $-\mathrm{b}$ & $40,0^{\mathrm{ab}}$ & $40,0^{\mathrm{ab}}$ & $50,0^{\mathrm{a}}$ \\
$8,0^{* * *}$ & $-\mathrm{b}$ & $40,0^{\mathrm{ab}}$ & $65,0^{\mathrm{a}}$ & $60,0^{\mathrm{a}}$ \\
$9,0^{* *}$ & $10,0^{\mathrm{b}}$ & $30,0^{\mathrm{ab}}$ & $65,0^{\mathrm{a}}$ & $70,0^{\mathrm{a}}$ \\
$10,0^{* *}$ & $8,3^{\mathrm{b}}$ & $75,0^{\mathrm{a}}$ & $100,0^{\mathrm{a}}$ & $100,0^{\mathrm{a}}$ \\
$11,0^{* * *}$ & $8,3^{\mathrm{b}}$ & $66,7^{\mathrm{ab}}$ & $91,7^{\mathrm{a}}$ & $66,7^{\mathrm{ab}}$ \\
$12,0^{* * *}$ & $8,3^{\mathrm{b}}$ & $66,7^{\mathrm{ab}}$ & $91,7^{\mathrm{a}}$ & $66,7^{\mathrm{ab}}$ \\
$13,0^{* * *}$ & $-\mathrm{b}$ & $100,0^{\mathrm{a}}$ & $87,5^{\mathrm{a}}$ & $87,5^{\mathrm{a}}$ \\
$14,0^{* *}$ & $-\mathrm{b}$ & $87,5^{\mathrm{a}}$ & $87,5^{\mathrm{a}}$ & $75,0^{\mathrm{ab}}$ \\
$15,0^{* * *}$ & $-\mathrm{b}$ & $62,5^{\mathrm{ab}}$ & $87,5^{\mathrm{a}}$ & $25,0^{\mathrm{ab}}$ \\
\hline
\end{tabular}

*início do tratamento com medicamentos, ${ }^{*} \mathrm{a}, \mathrm{b}, \mathrm{c}$ Médias com expoentes diferentes, na mesma linha, diferem por pelo menos $\mathrm{P}<0,05$.

ITRA: grupo tratado itraconazol, TERB20: grupo tratado terbinafina dose $20 \mathrm{mg} / \mathrm{kg}$, TERB30: grupo tratado terbinafina dose $30 \mathrm{mg} / \mathrm{kg}$, CONT: grupo controle

TABELA 3

Avaliação histopatológica das lesões do ponto de inoculação dos grupos experimentais nas três necropsias realizadas.

\begin{tabular}{|c|c|c|c|}
\hline Grupos & Necropsia 1 & Necropsia 2 & Necropsia 3 \\
\hline \multirow[t]{5}{*}{ Terb20 } & Piogranulomas focais e & Granulomas e & Granulomas e \\
\hline & multifocais & piogranulomas focais e & piogranulomas focais e \\
\hline & Células leveduriformes em & multifocais & multifocais \\
\hline & brotamento & Lesões crônicas & Invasão óssea \\
\hline & & Células leveduriformes & Células leveduriformes \\
\hline \multirow[t]{5}{*}{ Terb30 } & Piogranulomas focais e & Granulomas e & Granulomas e \\
\hline & multifocais & piogranulomas focais e & piogranulomas focais e \\
\hline & Células leveduriformes em & multifocais & multifocais \\
\hline & brotamento & Lesões crônicas & Invasão óssea \\
\hline & & Células leveduriformes & Células leveduriformes \\
\hline \multirow[t]{6}{*}{ ITRA } & Granulomas e & Piogranulomas & Lesões cicatrizadas, \\
\hline & piogranulomas focais e & multifocais em processo & fibrose e ausência de \\
\hline & multifocais & resolução com & Células leveduriformes \\
\hline & Lesões crônicas & predomínio de fibrose, & \\
\hline & Células leveduriformes & Ausência & \\
\hline & & células leveduriformes & \\
\hline \multirow[t]{5}{*}{ CONT } & Granulomas e & Granulomas e & Granulomas focais \\
\hline & piogranulomas focais e & piogranulomas focais e & Células leveduriformes \\
\hline & multifocais & multifocais & \\
\hline & Lesões crônicas & Lesões crônicas & \\
\hline & Células leveduriformes & Células leveduriformes & \\
\hline
\end{tabular}

ITRA: grupo tratado itraconazol, TERB 20: grupo tratado terbinafina dose 20mg/kg, TERB 30: grupo tratado terbinafina dose 30mg/kg, CONT: grupo controle. 
Havia presença de células leveduriformes nos grupos TERB20, TERB30 e CONT, em todas as necropsias realizadas (semanas 9, 12 e 15), enquanto no grupo ITRA não foram observadas células fúngicas. Nos grupos TERB20 e TERB30, foi observada invasão das células leveduriformes nas vértebras coccígeas e em um animal do grupo TERB20 verificou-se lesão na cauda e na avaliação histopatológica demonstrou-se a presença de corpos asteróides.

\section{DISCUSSÃO}

Os animais experimentais tratados com itraconazol apresentaram ao final do experimento lesões cicatrizadas. Esses resultados confirmam a boa atividade do fármaco, sendo este considerado o tratamento de eleição para as formas cutâneas e cutâneas-linfáticas da micose. Outros estudos também demonstraram a ação do itraconazol em pacientes com esporotricose, nas doses variando de 100 a $400 \mathrm{mg} / \mathrm{dia}^{2} 3412$. Em animais, é o antifúngico mais utilizado na clínica, sendo recomendado nas doses de $5-10 \mathrm{mg} / \mathrm{kg}$ uma vez ao dia para o tratamento da esporotricose canina e felina, apresentando, normalmente, boa tolerabilidade para essas espécies ${ }^{13}$.

Em relação à terbinafina, não houve diferenças nos grupos tratados em relação ao controle, demonstrando que o fármaco utilizado nessas condições experimentais não foi efetivo no tratamento da esporotricose cutânea. Vários estudos resultaram na boa atividade in vitro do fármaco frente ao Sporothrix schenckii com CIMs menores ou iguais a outros antifúngicos utilizados para o tratamento da micose. Estudos clínicos também obtiveram boa resposta terapêutica com o uso do fármaco nas doses que variaram de 125 a $1.000 \mathrm{mg} / \mathrm{dia}$ em pacientes com as formas cutâneas e linfocutâneas da esporotricose $\mathrm{e}^{15}$. Provavelmente, os resultados clínicos obtidos no estudo tenham sido influenciados pelas doses e diluente utilizados para a terbinafina. Outros estudos realizados demonstraram que a ação do fármaco é dose-dependente, sendo que obtiveram melhores resultados em pacientes com esporotricose linfocutânea, quando administrada doses maiores ${ }^{15}$. Assim como as doses, o diluente é um outro fator que pode influenciar na concentração plasmática do fármaco. Em estudo realizado, os autores demonstraram que a terbinafina quando diluída em uma solução contendo 5\% de DMSO e $1 \%$ de tween 20 apresentou as maiores concentrações plasmáticas do fármaco ${ }^{6}$.

Em relação às lesões observadas no estudo, essas foram semelhantes às observadas por outros autores em que reproduziram a forma subcutânea da micose com a disseminação do microrganismo ${ }^{12}$. A regressão das lesões disseminadas detectadas no estudo também foi descrita na literaura em que os autores observaram que ratas inoculadas com Sporothrix schenckii apresentaram uma boa resposta tanto na imunidade humoral como na mediada por células, ocasionando uma regressão da enfermidade aos 30 dias de infecção ${ }^{10}$. A considerável diminuição das lesões disseminadas em $75 \%$ dos ratos ao final do experimento sugere o desenvolvimento de imunidade adquirida contra o Sporothrix schenckii, durante o período experimental.
A partir do cultivo das amostras, foi possível obter o retroisolamento do Sporothrix schenckii, resultando na análise macroscópica e microscópica das colônias cutivadas a $25^{\circ} \mathrm{C}$ e posteriormente a $37^{\circ} \mathrm{C}$ para confirmação do dimorfismo do agente. Estes resultados também foram obtidos por outros autores $^{71017}$.

Os animais tratados com itraconazol demonstraram no exame histopatológico ausência de células fúngicas, ao passo que no grupo controle e nos grupos tratado terbinafina foi observado a presença de células leveduriformes em brotamento, lesões piogranulomatosas e granulomatosas com infiltrados de células gigantes e células epitelióides. As lesões histológicas demonstradas no presente estudo foram semelhantes às descritas em outros trabalhos que demonstraram a presença das lesões piogranulomatosas e granulomatosas clássicas da micose $\mathrm{e}^{114}$.

\section{AGRADECIMENTOS}

Ao CNPq, a CAPES (Bolsa de pós- graduação); a FAPERGS; Novartis e Janssen-Cilag

\section{REFERÊNCIAS}

1. Coskun B, Saral Y, Akpolat N, Ataseven A, Ciçek D. Sporotrichosis successfully treated with terbinafine and potassium iodide: case report and review of the literature. Mycopathologia 158: 53-56, 2004.

2. Costa R0, Zeitune T. Lynphocutaneous sporothrichosis treated with terbinafine. In: Resumos do XIV Congresso of the International Society for Medical and Veterinary Mycology, Buenos Aires p. 160, 2000.

3. De Lima Prearo CA, Daniguchi DP, Martinez MA, Landman G, Paschoal LH. Case report: bilateral sporotrichosis. Mycoses 45: 415-417, 2002.

4. Hampton DE, Adesina A, Ghodosh J. Conjuctivial sporotrichosis in the absence of antecedent trauma. Cornea 21: 831-833, 2002.

5. Hull PR, Vismer HF. Treatment of cutaneous sporotrichosis with terbinafine. British. Journal of Dermatology 126: 51-55, 1992.

6. Kan VL, Bennett JE. Efficacies of four antifungal agents in experimental murine sporotrichosis. Antimicrobial Agents and Chemotherapy 32: 1619-1623, 1988.

7. Lacaz CS, Porto E, Martins JEC, Heins-Vaccari EM, Melo NT. Tratado de Micologia Médica. Editora Savier, São Paulo, 2002.

8. Meinerz AR, Nascente PS, Schuch LFD, Cleff MB, Santin R, Brum, CS, Nobre MO, Meireles MCA, Mello JRB. Suscetibilidade in vitro de isolados de Sporothrix schenckii frente à terbinafina e itraconazol. Revista as Sociedade Brasileira de Medicina Tropical 40: 60-62, 2007.

9. Morishita N, Yamazaki K, Ninomiya J, Hamaguchi T, Sei Y, Takiuchi I. A case of lymphocutaneous sporotrichosis. Nippon Ishinkin Gakkai Zasshi 42:149-154, 2001.

10. Mujica MT, Agotegaray M, Canoba A, Delasoie P, Hauswirth S, Kociski G, Tartabini M, Alvarez D. Esporotricosis experimental en ratas. Revista Argentina de Micologia 15: 7-12, 1992.

11. Nakamura Y, Sato H, Watanabe S, Takahashi H, Koide K, Hasegawa A. Sporothrix schenckii isolated from a cat in Japan. Mycoses 39:125-128, 1996.

12. Polania LAG, Alzate A, Saraiva N. Comportamiento experimental del Sporothrix schenckii y la Leishmania mexicana em el hamster. Revista do Instituto Tropical de São Paulo 32: 319-324, 1990.

13. Rochette F, Engelen M, Vanden, Bossche H. Antifungal agents of use in annimal health-practical aplications. Journal of Veterinary Pharmacology and Therapeutics 26: 31-53, 2003. 
14. Schubach TM, Schubach A0. Esporotricose em cães e gatos-revisão. Revista Clínica Veterinária 29: 21-24, 2000.

15. Souza LL, Nascente PS, Nobre MO, Meinerz ARM, Meireles MCA. Isolation of Sporothrix schenckii from the nails of healthy cats. Brazilian Journal Microbiology 37: 303-305, 2006.
16. Stalkup JR, Bell K, Rosen T. Disseminated cutaneous sporotrichosis treated with itraconazole Cutis 69: 371-374, 2002.

17. Yoshiike T, Lei P, Komatsuzaki H, Ogawa H. Antibody raised against extracellular proteinases of Sporothrix schenckii in S. schenckii inoculated hairless mice. Mycophatologia 123:69-73, 1993. 